\title{
Da Guiné-Bissau à Colômbia. Benkos Biohó, resistência e (é) palenque. Um caso da diáspora africana ${ }^{*}$
}

De Guinea-Bissau a Colombia. Benkos Biohó, resistencia y (es) Palenque. Un caso de la diáspora africana

From Guinea-Bissau to Colombia. Benkos Biohó, resistance and (is) Palenque. A case of the African Diaspora

* Estudante do último semestre de Sociologia da Universidad del Valle. Atualmente é professor de português no Centro de Estudios Brasileros (CEBRAS). Seus interesses de pesquisa são: relações raciais, racismo, diáspora africana, resistência negra, San Basilio de Palenque e ações afirmativas. Correio eletrônico: henryibu@gmail.com

${ }^{* *}$ Artigo reflexão recebeu a 06/07/2015 e aceitado 20/07/2015. 



\section{Resumo}

Resumen

Abstract

Neste texto refiro-me ao caso de Benkos Biohó como uma figura simbólica da resistência africana, afrodescendente e afrocolombiana dada desde os palenques (no Brasil utiliza-se a expressão "quilombos"), manifestações de resistência que começaram na África e mais tarde se reproduziram na América toda durante o tráfico de pessoas, a colonização e a escravização. Hoje estas estratégias estão sendo reinventadas e reformuladas pelos afrodescendentes, mulheres e homens, que nestes territórios se localizam. Quanto às formas ou métodos, foram sempre diversos, desde a luta armada até a exigência de liberdade nos tribunais. Mas sempre procuraram avanços, melhoras e progresso em um sistema opressor colonial.

\section{PALAVRAS CHAVE:}

Movimento afrodescendente | resistência africana | palenque | Benkos Biohó

En este texto hago referencia al caso de Benkos Biohó como una figura simbólica de la resistencia africana, afrodescendiente y afrocolombiana dada desde los palenques (en Brasil se utiliza la expresión "quilombos"), manifestaciones de resistencia que comenzaron en África y más tarde se reprodujeron en toda América durante el tráfico de personas, la colonización y la esclavización. Hoy estas estrategias están siendo reinventadas y reformuladas por los afrodescendientes, mujeres y hombres, que se localizan en estos territorios. En cuanto a las formas y los métodos, éstos fueron siempre diversos, desde la lucha armada hasta la exigencia de libertad en los tribunales. Pero siempre buscaron avances, mejoras y progreso en un sistema opresor colonial.

\section{PALABRAS CLAVE:}

Movimiento afrodescendiente | resistencia africana | palenque | Benkos Biohó.

In this article I mention the case of Benkos Biohó as a symbolic figure of the african, afrodescendant and afrocolombian resistance, conducted by the "palenques" (known as "quilombos" in Brazil), manifestations of resistance that started in Africa and were reproduced later in America during human traffic, colonization and enslavement. Today, this strategies 
are reinvented and reformulated by the afrodescendants, women and men, that live in this territories. Regarding the ways and methods, these were always diverse, from the armed fight to the freedom demands in courts. But they always looked for advances, improvements and progress in an opressor colonial system.

\section{KEYWORDS:}

Afrodescendant movement | african resistance | palenque | Benkos Biohó 


\section{Palenque, primeiro povo livre da América}

Ao falarmos em "palenque" estamos fazendo uma referência explícita à resistência que se deu na Colômbia por parte de africanos e afrodescendentes que durante a época da colônia foram escravizados. O termo "Palenque" pode ser entendido como uma organização social de africanos e africanas (com o passar do tempo, afrodescendentes) que, fugidos dos seus lugares de exploração e escravização, conformavam um território livre e autônomo. Nele, desenvolviam as suas práticas culturais africanas: ritos, danças, modos de viver, língua, etc., encaminhando-as à construção de um espaço de liberdade que tivesse em conta a situação de opressão constante do momento. Portanto, foi um lugar a partir do qual recriou-se um pedaço da África na América e constituiu a maior manifestação de resistência no período colonial. Apoiado no texto do antropólogo Aquiles Escalante (2005):

"O Palenque de San Basilio, o mais vigoroso (forte) movimento de insurreição escravista,
conhecido no litoral colombiano do Caribe, aconteceu em Cartagena de Indias no começo
do século XVII, sendo governador Dom Jerónimo de Suazo Casasola, que começou a
exercer as suas funções governamentais ao redor do ano 1600 . O primeiro em reagir pu-
blicamente foi o teimoso e ousado Domingo Bioho, ex-monarca de um estado africano, o
qual, encabeçando um grupo de trinta negros e negras embrenhou-se no arcabuco (significa
lugar de difícil acesso em espanhol) e pântano de Matuna, no sul da vila de Tolú" (2005:387)

Para reconhecer e entender melhor este processo que caracteriza a história da Colômbia, deve-se começar indicando que San Basilio de Palenque nasceu com base no trabalho que tinha sido feito pelo líder africano Benkos Bioho e outros guerreiros e guerreiras africanos num palenque anterior chamado Palenque da Matuna. Este palenque resistiu fortemente às investidas da coroa espanhola no início do século XVII; nesse sentido, pode-se dizer que se criaram as bases para que os afrodescendentes interiorizassem as formas de resistência, desde as construções das casas até a organização interna, e após a morte do Biohó, criarem San Basilio de Palenque. É por isso que na tradição oral desta comunidade Benkos Biohó aparece como o seu fundador. Ele fez com que se espalhassem pelo território nacional, deixando as bases para que fossem construídos mais palenques. Portanto, a organização preservou as características dos palenques mais antigos.

Quanto à fundação de San Basilio de Palenque não há um consenso. As resistências sob a forma de palenques têm sido documentadas com referência a várias datas e vários lugares. Algumas fontes revelam a existência de San Basilio de Palenque a partir do 
século XVI, outras do XVII e igualmente do XVIII. Nesta análise opto pela opção que remete à origem no século XVII. Como lembra Jaramillo (1989):

\begin{abstract}
"Para significar uma agrupação de escravos cimarrones, mais ou menos permanente, o termo só aparece no século XVIII. Possivelmente foi o Palenque de San Basilio formado nos começos do século XVII (160o), na governação de Cartagena, aquele que deu a base para que se chamasse palenques a estas comunidades de escravos" (1989:60)
\end{abstract}

O avanço na organização da comunidade já era então para o século XVII um elemento de preocupação para os espanhóis que tentaram eliminar, por meio do extermínio físico, estas populações que resistiram de diversas formas.

O crescimento de San Basilio está ligado à importância de Cartagena como cidade principal no que se refere à chegada de africanos escravizados na América. Ali negociavam-se seres humanos como se fossem mercadorias, encaminhavam-se para o interior do país e para outras partes do continente, pois era o principal porto de chegada no caribe colombiano durante o século XVI e XVII (Curtin, 1969).

É necessário dizer que existiram muitos palenques ao redor do país, do norte ao sul, do leste ao oeste. Assim que os africanos e africanas eram trazidos cruzando o oceano numa viagem sem retorno, resistiam-se à condição imposta na América. Nem todos sobreviveram, porque a coroa espanhola tentou desde o primeiro momento desestabilizá-los, derrubá-los, ou seja, acabar com eles. Como narra Jaramillo (1989):

\footnotetext{
“Segundo Fray Pedro Simón, foi organizado pelo negro Dionisio Bioho, para 1599 ou 1600, sendo governador de Cartagena Dom Jerónimo Suaze ou Suazo Casasola. As autoridades espanholas tentaram inutilmente eliminar os palenqueiros, até que no ano de 1612 ou 1613 resolveram reconhecer-lhes a liberdade e o direito a viver com certa autonomia" (1989:61)
}

Porém, não foi uma tarefa bem sucedida porque a capacidade de luta foi maior e a comunidade que hoje conhecemos com o nome de San Basilio de Palenque é uma prova disso, é considerado "O primeiro povo livre da América".

$\mathrm{Na}$ verdade, a existência dos palenques representava uma ameaça muito grande para os objetivos dos europeus naquela época. Nesses lugares, reconstruíam seus costumes africanos, praticavam seus ritos, falavam sua língua, etc. Em face desta situação o medo dos espanhóis já era evidente. Segundo Arrázola (1970) era tão bélica a situação em Cartagena que "era possível o aparecimento de um Haiti há muito tempo atrás":

"O terrível da descrição do Governador, tanto pelas tropelias cometidas pelos cimarrones como pelas retaliações dos que saíram a debelá-las, não precisa de encarecimento. No endecassílabo: "coisas foram do tempo, não da Espanha”. Como de tempo atrás foi o roubo das sabinas pelos romanos, feito novamente pelos cimarrones. Mas não se pode deixar 
passar sem anotar o fato de que Dom Gerónimo de Suazo e mesmo Casasola qualifica de "guerra" a ação que se adiantava contra os cimarrones; e, tem mais, quando o governador sugere que os negros de intramuros chegaram a um estado de insolência que foi preciso castigá-los (flagelando-os e torturando-os) para depois jogá-los em embarcações, ou seja, condená-los ao remo, descrevendo um estado de revolta geral dos escravos santo levantados como subjugados, que havia de confrontar-se repetidamente na época da Colônia em Cartagena, ao ponto que em 1694 faltou pouco para que na nossa região florescesse um Haiti negro duzentos anos antes do Haiti antilhano" (1970:38)

\section{A origem de Benkos Biohó}

Os africanos e africanas trazidos ao território da "Nueva Granada" chegaram de vários lugares da África. É difícil estabelecer com precisão qual foi exatamente a origem do herói. Ainda é um debate muito amplo devido às fontes que se tem. Embora seja bem complexo, há referências que permitem dar algumas possíveis afirmações. Hoje em San Basilio de Palenque é praticado um ritual conhecido como "Lumbalú". É um ritual funerário que acontece quando alguém morre na comunidade. Este é um pedaço da música que se canta no ritual (Friedemann, 1998:5):
chi ma nlongo
(soy de) los del Congo
chi ma (ri) Luango
(soy) los de Luango
Chi ma ri Luango ri Angola
De los Luango de Angola

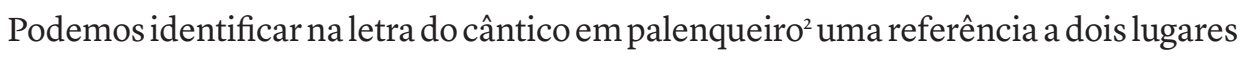
na África: Angola e Congo. Dita referência revela uma origem étnica da comunidade palenqueira. No entanto, se pensarmos no líder Benkos Biohó, o sobrenome que em alguns textos aparece como Bioo, Bissagó ou Bijagó, já nos dá algumas dicas da sua origem. O nome "Bijagó" faz referência ao Arquipélago dos Bijagós na Guiné-Bissau.

No livro “Son Ri Tambó” (Som de tambores) da Fundación Transformemos (2011), encontramos em palenqueiro:

\footnotetext{
“Jué posible ke Benko Biojó a nasé andi un paraje ri Nginéa Bissau, andi Afrika Osirentá, ñamáo Biojó, i ke posá si sendába andi Isla Bijago o Bissajo. Ma omble bisajo kumo Benko o Romingo, aseba ma usulú, ku fofogen pa makaniá kumo boga i chupungún, pó ta ku e makaniá á ndulo é topá kumo ele ajuí i atá bibí mu maluko kumo sienega” (2011:25)
}

2. Esta língua é uma mescla de espanhol, línguas africanas e talvez um português arcaico (Dieck, 1998). Alguns estudos mostram que há uma presença de palavras de origem kimbundo e kikongo (língua Bantu) no palenqueiro (Friedemann, 1998; Rosselli, 2010). 
Em português: "É possível que Benkos Biohó tenha nascido em um lugar da GuinéBissau, na África Ocidental, chamado Biohó, e que o seu lar tenha ficado nas Ilhas Bijago ou Bissajo. Os homens bijagos, como Benkos ou Domingo, eram guerreiros, excelentes navegadores e nadadores, por causa disso, talvez, desenvolvendo o difícil ofício de vogar, achou a forma de fugir e se organizar em terrenos difíceis como o pântano".

Então vemos como a figura de Benkos Biohó, junto com a formação dos palenques, representa esse diálogo entre a África e a América, envolvida nesse processo tão significativo na história da humanidade como foi a diáspora africana. Nesse sentido, torna-se central para entender a configuração de San Basilio de Palenque hoje, que, com aproximadamente 4000 habitantes, é uma das maiores mostras da África na Colômbia e na América. De fato, ao chegar a San Basilio há uma estátua do líder africano, que serve como elemento de identidade na comunidade. A figura de Benkos Biohó se encontra nas histórias dos mais velhos até os mais jovens e, de certa forma, simbolicamente contribui para a manutenção da memória cimarrona (Ver Anexo 1).

\section{Considerações finais}

Há todo um debate em relação aos termos e noções utilizadas para descrever estes processos históricos. Em meu ponto de vista, a linguagem está carregada de inúmeros significados simbólicos que manifestam um olhar sobre as coisas, uma percepção, um sentir. O ditado: "a história é escrita pelos vencedores" tem tudo a ver com isso. Nesse intuito de entender estes temas, penso que se deve ter muito cuidado com os conceitos e não desconhecer que eles fazem parte de uma visão de mundo carregada de subjetividades próprias dos sujeitos que descrevem, analisam e emitem um discurso.

Assim sendo, utilizo a categoria "escravizado" em vez de "escravo", pois a categoria escravizado explica melhor o processo histórico pelo qual passaram milhares de seres humanos, aos quais pretendeu-se tirar toda sua humanidade, procurando torná-los peças intercambiáveis e objetos.

Os espanhóis desejaram fazer dos africanos, mercadorias e coisas. Nunca humanos. É fundamental, portanto, entender que no caminho de tornar uma população "escrava" que trabalhasse nas plantações de cana de açúcar, nas fazendas, na mineração, e nas diversas atividades exploradoras e escravizantes, impuseram-lhes as piores condições, sem participação na vida política, econômica, religiosa, empresarial, ou seja, nas esferas que representam o poder. Junto com isso veio um processo racista e discriminatório que pretendeu fazer desse povo um conjunto de pessoas violentamente pacíficas, cheias de passividade e desorganização. Mas não foi isso o que aconteceu. Pelo contrário, os africanos e africanas conseguiram contestar esta situação e mesmo com as diferenças étnicas presentes, a organização social foi um fato. 
Diante desta situação, as pessoas vindas de diversos lugares da África organizaram-se para contestar essa nova realidade, então optaram por fugir da opressão e construir a sua própria realidade, afastando-se dos lugares nos quais eram escravizados. Nesse sentido, os Palenques eram formados pelos chamados "cimarrones" (maroons em inglês; marons em francês), eram seres humanos africanos que fugiam das fazendas e da escravização. Dada a importância dessa forma de resistir, o elemento da "ação coletiva" foi fundamental. A formação dos palenques tem que ser entendida como uma resistência coletiva, de vários indivíduos, homens e mulheres, os quais agiram, com uma consciência étnico-racial, com o objetivo de derrocar o sistema escravista e estabelecer-se em comunidades livres ao redor do território. Não pode ser explicada como se fosse totalmente individual e feita por uma pessoa só. Em vista disso, a figura do Benkos Biohó como imagem do líder é analisada sem apagar o trabalho dos outros que também tornaram possível a resistência. Com isto quero dizer que ele não lutou sozinho, senão com um conjunto de mulheres e homens que sob a mesma condição agiram radicalmente.

\section{Referências}

ARRÁZOLA, R. (1970). Palenque, primer pueblo libre de América: Historia de las sublevaciones de los esclavos de Cartagena. Cartagena: Ediciones Hernández.

CURTIN, P. D. (1969). The Atlantic Slave Trade: A census. Madison: The University of Wisconsin Press.

DIECK, M. (1998). Criollística afrocolombiana. En: A. Maya (ed.). Geografia humana de Colombia. Tomo VI, (pp. 79-102). Bogotá: Instituto Colombiano de Cultura Hispánica.

ESCALAnte, A. (2005) Palenques en Colombia. Revista del CESLA, 385-39o.

FRIEDEMANN, N. S. DE. (1998). San Basilio en el universo kilombo-África y Palenque-América. En: A. Maya (ed.). Geografía Humana de Colombia. Tomo VI, (pp. 79-102). Bogotá: Instituto Colombiano de Cultura Hispánica.

FUNDACIÓN TRANSFORMEMOS. (2011). Son ritambó. [Cartilla didáctica para trabajar Palenque y lengua palenquera].

JARAMILLO, J. (1989). Ensayos de historia social. Bogotá: Tercer Mundo Editores.

ROSSELLI, C. P. (2010). El idioma Criollo de San Basilio de Palenque. En: Publicación de la Academia Colombiana de la Lengua, Número 21, Abril, Bogotá-Colombia. 


\section{Anexo}

\begin{tabular}{|l|l|}
\hline $\mathbf{1}$ & Estátua do líder Benkos Biohó em San Basilio de Palenque \\
\hline
\end{tabular}

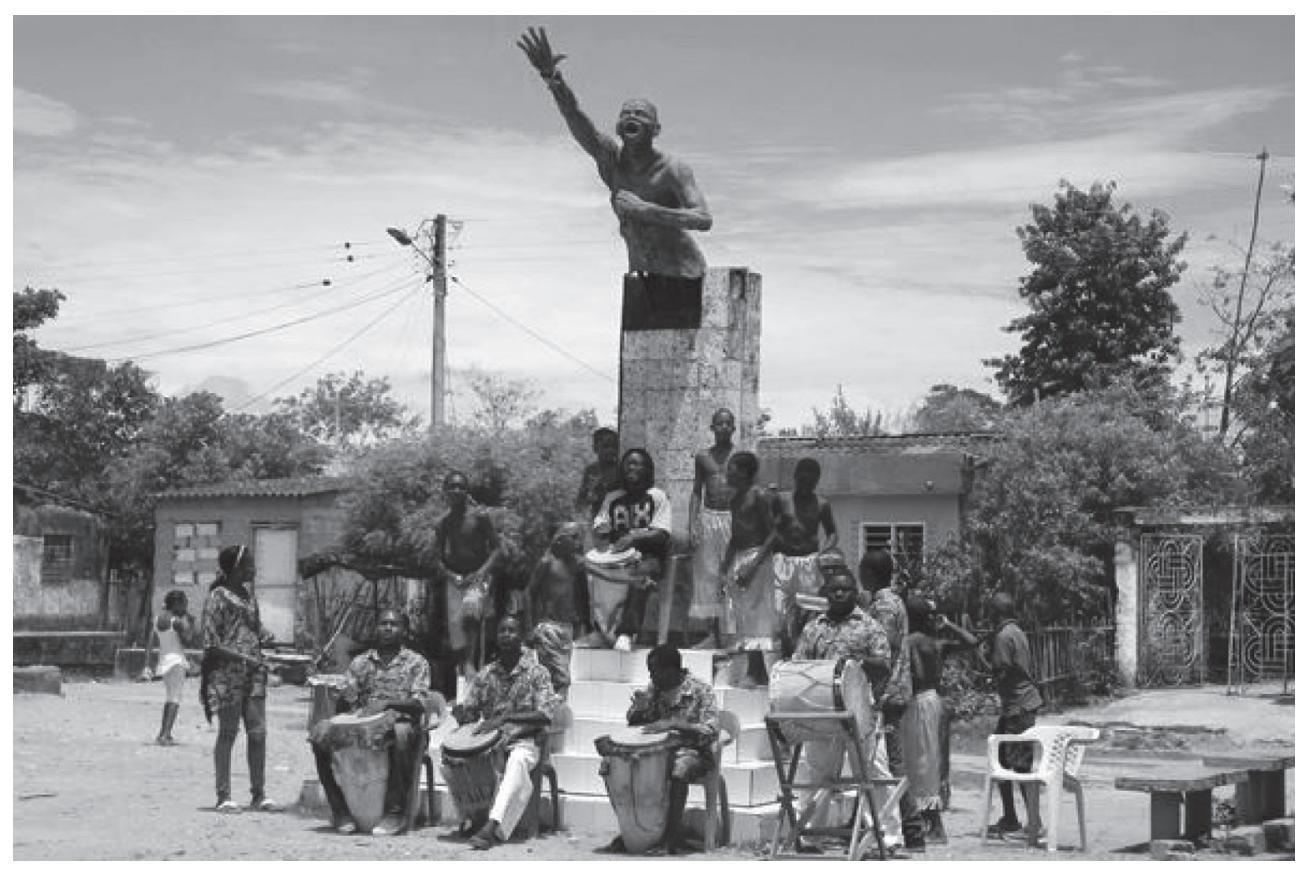

Foto: EFE/Ricardo Maldonado1

1. Recuperado http://www.elmundo.com/portal/noticias/internacional/una_cadena_pendiente_de_romper.php (15 dezembro de 2014) 